\title{
An Airway Wallstent for the treatment of tracheobronchial malignancies
}

\author{
C T Bolliger, M Heitz, R Hauser, R Probst, A P Perruchoud
}

\begin{abstract}
Background - The palliative effect of a new Airway Wallstent with a polyurethane covering was tested in patients with inoperable malignant lesions of the central airways.
\end{abstract}

Methods - Thirty six stents were inserted in 27 patients with obstruction $(n=24)$ or fistulae $(n=3), 15$ of whom later received radiotherapy. The degree of symptom relief was assessed 1, 30, and 90 days after stent insertion.

Results - Stent deployment was successful in all patients. Significant improvements were observed one day after placement compared with before placement, with no change at 30 and 90 days, in dyspnoea index (mean (SD) $3.2(0.7)$ before stent insertion compared with $1.8(0.7)$ one day after insertion); Karnofsky index (32 (18) before insertion compared with 55 (15) one day after insertion); and obstruction of airway diameter $(85$ (11)\% before insertion compared with 10 (12)\% on day 1 after stent insertion). Stent-related complications needing later interventions included retained secretions (five patients), granuloma formation at ends of the stent (four patients), and stent migration (four patients). Over a median observation period of two months (range two days to 8.5 months) all stent coverings remained intact without delamination or tumour ingrowth.

Conclusions - The Airway Wallstent provided excellent palliation for malignant obstructions and fistulae of the central airways. Retention of secretions and granuloma formation at the ends of the stent warrant minor technical improvements.

(Thorax 1996;51:1127-1129)

Keywords: tracheobronchial malignancies, interventional pulmonology, endoscopic treatment, stents.

\section{ENT Department}

\section{R Hauser}

R Probst

University Hospital Basel, 4031 Basel,

Switzerland

Stadtspital Triemli, Zurich, Switzerland M Heitz

Correspondence to: Dr C T Bolliger.

Received 28 June 1995 Returned to authors 23 October 1995

Revised version received 2 April 1996

Accepted for publication

30 May 1996
Various stent models are used for the endoscopic treatment of inoperable stenoses of the central airways, of which the silicone stent (Endoxane) designed by Dumon ${ }^{12}$ is currently the most widely used. Apart from various other silicone stents, ${ }^{3}$ metal stents have also been used widely ${ }^{4}$ but their long term results are often disappointing. Tumour ingrowth through the wire mesh often occludes the stent within 2-3 months of placement, ${ }^{5}$ and in benign disease the same problem arises from granuloma formation. ${ }^{6}$ With an additional covering, metal stents might become more useful with their favourable wall to inner diameter ratio and their excellent adaptability to varying airway wall diameters and near absence of kinking. A new covered Wallstent, the Airway Wallstent, has been developed by Schneider (Europe) AG, Bülach, Switzerland. We have evaluated the long term results of its use in patients with stenoses and fistulae due to malignancies of the tracheobronchial tree.

\section{Methods}

PATIENTS

Twenty seven patients ( 20 men) of mean age 60 years (range $41-78$ ) were treated with one or more Wallstents. They all presented with inoperable malignant lesions of the central airways. The diagnoses were 21 bronchogenic carcinoma, three oesophageal carcinoma, two thyroid carcinoma, and one lymphoma. After endoscopic treatment (Nd:YAG laser resection and/or dilatation) with the rigid bronchoscope under general anaesthesia, 24 patients exhibited residual obstruction of $>50 \%$ of the airway and three patients suffered from malignant fistulae without stenosis (one tracheooesophageal, one left broncho-oesophageal, and one bronchopleural stump fistula after right pneumonectomy).

\section{STENT SPECIFICATIONS AND INSERTION}

TECHNIQUE

The Airway Wallstent is a self-expandable stent made of woven stainless steel filaments. The unconstrained stent dimensions designed for the airways were: diameters $12,14,16$, and $18 \mathrm{~mm}$; lengths: $25,30,35,45$, and $60 \mathrm{~mm}$. The stents have a polyurethane covering on the outside. The high flexibility of the stent is not altered because of the additional covering (fig 1). There are two different delivery devices: a flexible device (Telestep) on which the stent

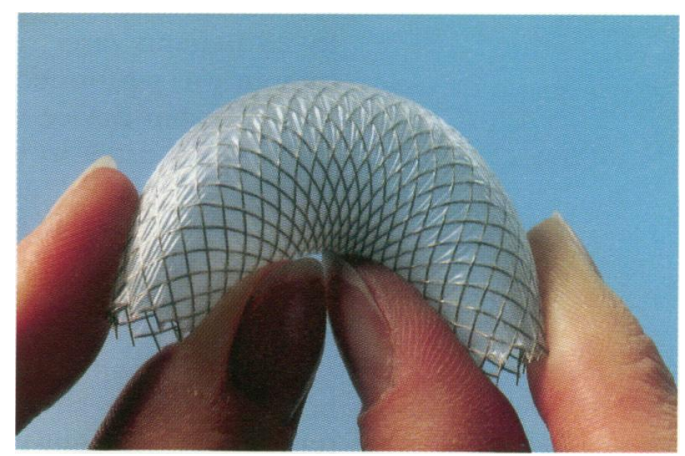

Figure 1 Airway Wallstent showing the new covering which does not impair its flexibility. 


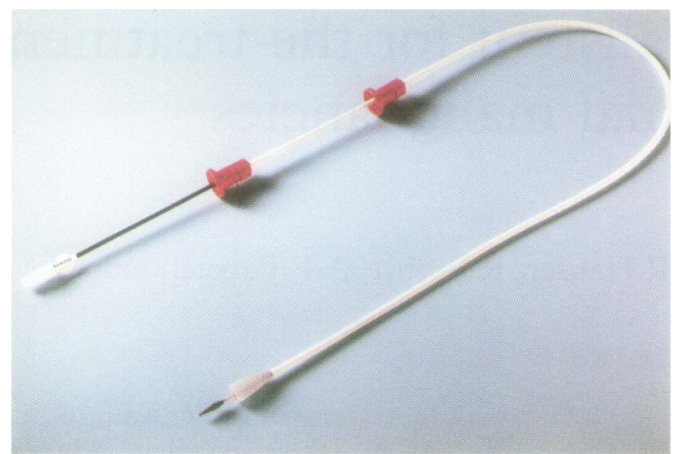

Figure 2 The flexible delivery device (Telestep) with a partially deployed stent visible at its distal end.

is mounted in a compressed and elongated shape (fig 2) and a specially designed rigid bronchoscope (Rigidstep). With the Telestep the radiopaque stent is usually deployed under fluoroscopic control through the bronchoscope. This device can be used for all lesions. With the Rigidstep the deployment procedure is controlled endoscopically by a rigid lens passed down the middle of the bronchoscope with the inside of the stent being visible. Stenotic lesions must have a lumen of $\geq 12 \mathrm{~mm}$ for the Rigidstep to pass them.

\section{ADDITIONAL TREATMENT}

Fifteen of the 27 patients underwent additional treatment with radiotherapy starting two weeks after stent placement; eight had external beam radiation and seven, who had exhausted this modality, underwent brachytherapy.

\section{ASSESSMENT OF OUTCOME}

The main outcome parameters assessed in all patients before and one, 30 , and 90 days after stent insertion were: (1) technical ease of stent delivery, and (2) efficacy of symptom relief assessed by changes in dyspnoea (WHO index) and Karnofsky indices, chest radiography, and bronchoscopy. The degree of obstruction was determined endoscopically (percentage diameter) or, in cases of death, by post mortem examination. All postoperative complications were recorded.

\section{Results}

STENT DELIVERY

In 23 patients laser resection of endoluminal tumour was performed before stent placement. The Telestep device was used in 23 patients and the Rigidstep in four, and all stents were able to be placed accurately. In the three patients with fistulae stent placement resulted in a tight seal.

A total of 36 stents were inserted in the 27 patients at the following sites: trachea (13 stents), left main bronchus (10), right main bronchus (eight, all in patients with advanced tumours of the right upper lobe), and trachea extending into the left main bronchus (five, all in patients after right pneumonectomy).

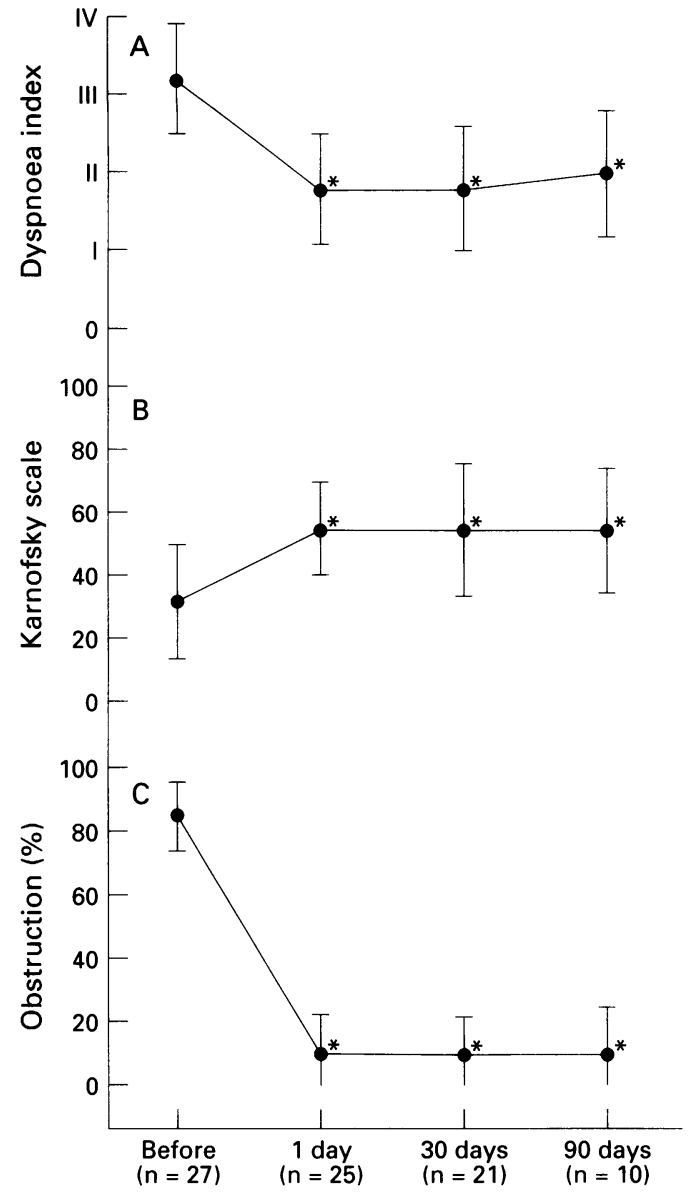

Figure 3 (A) WHO dyspnoea index, (B) Karnofsky scale, and $(C)$ degree of obstruction in 27 patients measured before and one, 30, and 90 days after stent placement. Values are mean $(S D) .{ }^{*} p<0.01$ compared with before stent placement.

EFFICACY OF PALLIATION AND STENT-RELATED COMPLICATIONS

A comparison of the dyspnoea scores, Karnofsky scale, and obstruction of the airway diameter before and after stent insertion showed significant and lasting improvements $(p<0.01)$ (fig 3). For dyspnoea the mean (SD) values before treatment and one, 30 and 90 days after insertion of the stent were $3.2(0.7)$, $1.8(0.7), 1.8(0.8)$, and $2.0(0.8)$, respectively, for the Karnofsky scale the scores were 32 (18), 55 (15), 55 (21), and 55 (20), and for percentage obstruction the values were 85 (11)\%, $10(12) \%, 10(12) \%$, and $10(15) \%$, respectively. Due to early deaths, only 25 patients could be analysed after one day, 21 after 30 days, and 10 after 90 days. The median observation period was two months (range two days to 8.5 months) with 18 patients dead and nine alive at the time of writing. The causes of death were tumour progression (seven), pneumonia (six), heart failure (three), pulmonary embolism (one), and haemoptysis (one), assessed by clinical diagnosis in nine cases and post mortem examination in the other nine.

Over the three month study period the following stent-related complications occurred which were diagnosed and dealt with at unplanned visits in 10 patients before day 30 and in five after day 30: retained secretions within the stent necessitating bronchoscopic as- 
piration (five), granuloma formation at the end of the stents necessitating careful laser resection, radiotherapy or additional stent placement (four), stent migration necessitating endoscopic stent removal (six). Two of the six migrations occurred after full dose external beam radiation with widening of the stented airway diameter beyond the unconstrained stent diameter. They had been expected and stent removal planned, so only four migrations were counted as complications related to the stent itself. The chest radiographs were helpful in detecting stent migration. In all patients the stent covering remained intact without delamination or tumour ingrowth during the follow up period of three months.

\section{Discussion}

The results of our study confirm the usefulness of the new covered Airway Wallstent for the relief of obstructions and sealing of fistulae in malignancies of the central airways. The polyurethane covering successfully prevented reobstruction of the area covered by the stent and, with a maximal follow up of 8.5 months, no deterioration of the covering or delamination was observed.

The insertion of the stents with the flexible or the rigid delivery device proved to be relatively simple. One caveat must be mentioned, however. The considerable shortening of the Wallstent, which is more pronounced when using the Telestep delivery device, makes the choice of adequate dimensions of the stent more difficult than with stents that do not shorten on placement. This problem is, however, overcome with increasing experience with the device.

Symptom relief was excellent and lasting, and comparable to the results obtained with silicone stents. ${ }^{1-3}$ The advantage of the Airway Wallstent over cylindrical silicone stents is its feasibility in narrow (diameter $<10 \mathrm{~mm}$ after dilatation) or conical stenoses or in stenotic airways with greatly varying diameters. It was particularly useful in the three patients with malignant fistulae. The optimal solution in these patients, in whom the disease is usually advanced and who therefore have a short life expectancy, is the sealing of the fistula through a tightly fitting stent. In our experience the available silicone stents, such as the Dumon or the dynamic Y stent, ${ }^{7}$ do not seal off fistulae in airways with normal diameters.

The Airway Wallstent had similar complications to those of silicone stents. The major difference was the retention of secretions which necessitated bronchoscopy in five $(19 \%)$ of the 27 patients. This propensity is probably due to the covering being on the outside of the stent with the wire mesh inside being a lot less smooth than a silicone surface.

The addition, of radiotherapy might well have enhanced the palliative effect of stent placement and, in our experience, represents an ideal therapeutic complement. ${ }^{2}$

In conclusion we found that the new Airway Wallstent is well suited for stenting of narrow airways or stenotic segments with varying diameters, and for sealing malignant fistulae in airways without concomitant stenosis. However, granuloma formation at the stent ends and retention of secretions within the stent remain problems which may be helped if the wire ends were blunted and the inside of the stent covered in order to smooth the inner surface.

This study was supported by Schneider (Europe AG), Bülach, Switzerland.

1 Dumon JF. A dedicated tracheobronchial stent. Chest 1990; 97:328-32.

2 Bolliger CT, Probst R, Tschopp K, Solèr M, Perruchoud AP. Silicone stents in the management of inoperable tracheobronchial stenoses. Indications and limitations. Chest 1993; 104:1653-9.

3 Cooper JD, Pearson FG, Patterson GA, Todd TRJ, Ginsberg RJ, Goldberg M, et al. Use of silicone stents in the management of airway problems. Ann Thorac Surg 1989;47: 371-8.

4 Rousseau H, Dahan M, Lauque D, Carré P, Didier A, Bilbao , et al. Self-expandable prostheses in the tracheobronchial tree. Radiology 1993;188:199-203.

5 Hürter T, Bohndorf K, Kropff M, Günther RW, Hanrath P. Bronchiale Endoprothesen (Stents) beim inoperablen Bronchuskarzinom. Pneumologie 1991;45:19-22.

6 Colt HG, Janssen JP, Dumon J-F, Noirclerc MJ. Endoscopic management of bronchial stenosis after double lung transmantation. Chest 1992;102:10-16.

7 Freitag L, Eicker R, Linz B, Greschuchna D. Theoretical and experimental basis for the development of a dynamic airway stent. Eur Respir $\mathcal{F} 1994 ; 7: 2038-45$. 